\title{
Analysis of Shunted Screen Gravel Pack Process and Calculation of Friction in Deepwater Horizontal Wells
}

\author{
Fei Xu, ${ }^{1}$ Shengtian Zhou $\mathbb{D}^{2}{ }^{2}$ Chong Zhang, ${ }^{1}$ Yi Yu, ${ }^{1}$ and Zhao Dong ${ }^{1}$ \\ ${ }^{1}$ CNOOC China Limited, Zhanjiang Branch, Zhanjiang, Guangdong 524957, China \\ ${ }^{2}$ China University of Petroleum, Qingdao, Shandong 266580, China
}

Correspondence should be addressed to Shengtian Zhou; stzhou2008@163.com

Received 22 September 2021; Accepted 15 November 2021; Published 12 December 2021

Academic Editor: Xiang Zhou

Copyright (C) 2021 Fei Xu et al. This is an open access article distributed under the Creative Commons Attribution License, which permits unrestricted use, distribution, and reproduction in any medium, provided the original work is properly cited.

\begin{abstract}
Shunted screen gravel packing is a kind of technology which is difficult to complete gravel packing with the conventional method in low fracture pressure formation and long wellbore length condition. According to the characteristics of LS 17-2 deepwater gas field, the shunted screen packing tool was designed and the gravel packing process and packing mechanism were analyzed. The variation law of the flow friction, flow rate distribution in multichannel, and other parameters of the shunted screen gravel packing were analyzed and calculated. The friction calculation model of different stages of gravel packing was established. A gravel packing simulation software was developed to simulate the friction in different stages of shunted screen gravel packing. The parameters such as sand-dune ratio, pumping sand amount, packing length, and packing time in the process of packing were also calculated. In deepwater horizontal well gravel packing, the results show that the friction ratio of the string is the largest in the stage of injection and $\alpha$-wave packing. While the friction increases rapidly in the stage of $\beta$-wave packing because the carrier fluid needs to flow through the long and narrow washpipe/screen annulus. Particularly when the $\beta$-wave packing is near the beginning of the open hole, the packing pressure reaches the maximum. The calculated results are in good agreement with the measured results of the downhole pressure gauge. The model and software can provide technical support for the prediction and optimization of gravel packing parameters in the future.
\end{abstract}

\section{Introduction}

For offshore deepwater oil and gas reservoir development, in order to reduce the number of wells and obtain higher sandfree production, sand control measures need to be taken. Gravel packing is the most commonly used sand control technology in the oil and gas industry [1-3]. In a conventional gravel pack, gravel slurry is injected into the wellbore/screen annulus, where gravel is packed into the wellbore/screen annulus to control formation sand entry into the wellbore. Due to the leakage of carrier fluid into the formation or shunt into the washpipe/screen annulus, the cross-section flow rate of carrier fluid decreases gradually along the flow direction, thus reducing the sand-carrying capacity of carrier fluid. The gravel in the wellbore/screen annulus is often blocked in advance, resulting in the premature sand bridge in the wellbore/screen annulus, especially in the long wellbore or low fracture pressure formation. For these special cases, despite the use of low-density gravel, the addition of drag reducers to the carrier fluid, multiple $\alpha$-wave or multiple $\beta$-wave packing, and other targeted countermeasures [4-7]. However, these methods can not ensure the success of gravel packing in some extreme cases. In the 1990s, shunted screen gravel packing was put forward [8], which was mainly used in casing gravel packing completion initially. With the extensive use of open hole completion gravel packing in offshore, gravel packing with shunted screen was gradually applied to open hole completion [9-22]. Although this technology is being used more and more widely, most of the field applications of this technology have not been specifically studied on the mechanism of shunted screen gravel packing. Particularly on the basis of this particular structural design, there is no quantitative description of the friction of each part of the shunted screen gravel packing. This paper mainly discusses the mechanism of shunted screen gravel packing, set up multichannel flow 
model, and friction calculation model for different flow stages. The corresponding software was developed to calculate flow parameters of the shunted screen multichannel and the friction calculation at the different stages. The calculated results are in good agreement with the data of LS 17-2 deepwater gas field in the South China Sea, which provides technical support for the design of shunted screen gravel packing in the future.

\section{Gravel Packing Mechanism of Shunted Screen}

The shunted screen pipe design is shown in Figure 1. Two types of tubes are welded outside the screen pipe in the wellbore/screen annulus, one is the transport tube and the other is the packing tube. The transport tube forms a continuous nonperforated pipe along the length of the screen pipe assembly. These transport tubes lead the slurry into the packing tube with the packing port through the multibranch pipe between each screen pipe joint, and then, the slurry flows to the wellbore/screen annulus through the packing tube. Both the transport tube and the packing tube are rectangular in cross section. Compared with the packing tube, the transport tube usually has a larger flow cross-section area. The cross section of the shunted screen pipe is shown in Figure 2.

The present design includes three transport tubes and two packing tubes, which are distributed in the wellbore/ screen annulus as shown in Figure 2.

In the process of gravel packing, due to the loss of carrier fluid to the formation or flowing to the washpipe/screen annulus, the sand-carrying capacity of carrier fluid decreases, the gravel concentration in the wellbore/screen annulus increases, and a large amount of gravel will deposit in this annulus. At this time, the wellbore/screen annulus may be blocked, forming a sand bridge. So the flow resistance in the wellbore/screen annulus will increase, and the slurry will be then led along the lower resistance channel into the shunted screen, across the blockage, and into the annulus behind the sand bridge to continue packing, as shown in Figure 3.

\section{The Establishment of Multichannel Mathematical Model}

Consider shunt system, it is a multichannel flow path system. The slurry into the wellbore/screen annulus from a crossover tool located in the beginning of the open hole flow along the wellbore/screen annulus. Carrier fluid may leak off into formation, and it also diverts through the screen into the washpipe/screen annulus. Once the blockage occurs in the wellbore/screen annulus, there is increased flow resistance. Meanwhile, the slurry will pass through the transport tube, enter the packing tube at the joint, and pack behind the plugging point. Suppose $Q_{p}, Q_{w}$, and $Q_{s}$ are the wellbore/ screen annulus flow rate, the washpipe/screen annulus flow rate, and the transport pipe flow rate, respectively, $\mathrm{m}^{3} / \mathrm{s}$. $Q_{p w}, Q_{p r}$, and $Q_{p s}$ represent the flow rate per unit length of

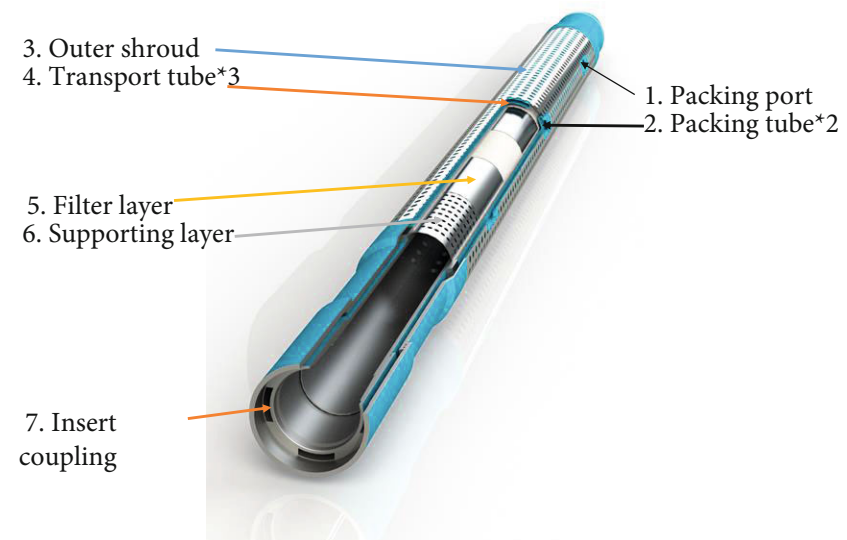

FIGURE 1: Shunted screen structure diagram.

the wellbore annulus through the screen to the washpipe/ screen annulus, the leakage rate per unit length into the formation and into transport pipe flow rate, respectively, $\mathrm{m}^{2} / \mathrm{s}$. $P_{p}, P_{w}, P_{s}$, and $P_{r}$, respectively, represent the wellbore/screen annulus pressure, washpipe/screen annulus pressure, transport tube pressure, and reservoir pressure, Pa. There are the following conservation equations [15].

\subsection{Mass Conservation Equation of Carrier Fluid.}

$$
\left\{\begin{array}{l}
\frac{\partial Q_{p}}{\partial x}+Q_{p w}+Q_{p s}+Q_{p r}=0 \\
\frac{\partial Q_{w}}{\partial x}-Q_{p w}=0 \\
\frac{\partial Q_{s}}{\partial x}-Q_{p s}=0
\end{array}\right.
$$

where $Q_{p w}, Q_{p r}$, and $Q_{p s}$ are functions of pressure difference of each flow channel, respectively, which can be expressed as

$$
\left\{\begin{array}{l}
Q_{p w}=f_{p w}\left(P_{p}-P_{w}\right), \\
Q_{p s}=f_{p s}\left(P_{p}-P_{s}\right), \\
Q_{p r}=f_{p r}\left(P_{p}-P_{r}\right),
\end{array}\right.
$$

where $f_{p w}, f_{p s}$, and $f_{p r}$ are the specific functional relationship between flow rate and pressure difference.

\subsection{Mass Conservation Equation of Gravel.}

$$
\left\{\begin{array}{l}
\frac{\partial\left(Q_{p} c_{p}\right)}{\partial x}+\frac{\partial\left(A_{p} c_{p}\right)}{\partial t}+Q_{p s} c_{p s}=0 \\
\frac{\partial\left(Q_{s} c_{s}\right)}{\partial x}+\frac{\partial\left(A_{s} c_{s}\right)}{\partial t}-Q_{p s} c_{p s}=0
\end{array}\right.
$$

where $A_{p}$ and $A_{s}$ are the cross-sectional areas of the wellbore/screen annulus and the transport tube, $\mathrm{m}^{2} ; c_{p}$ and $c_{s}$ are the gravel concentration in the wellbore/screen annulus and the transport tube, respectively, dimensionless; and $c_{p s}$ 


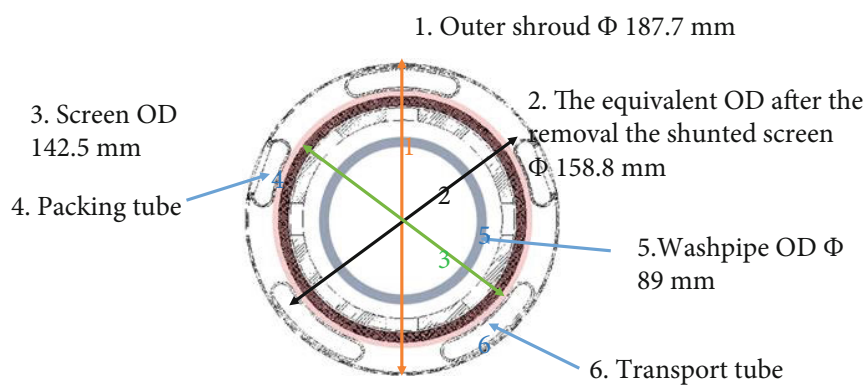

FIGURE 2: Shunted screen cross section.

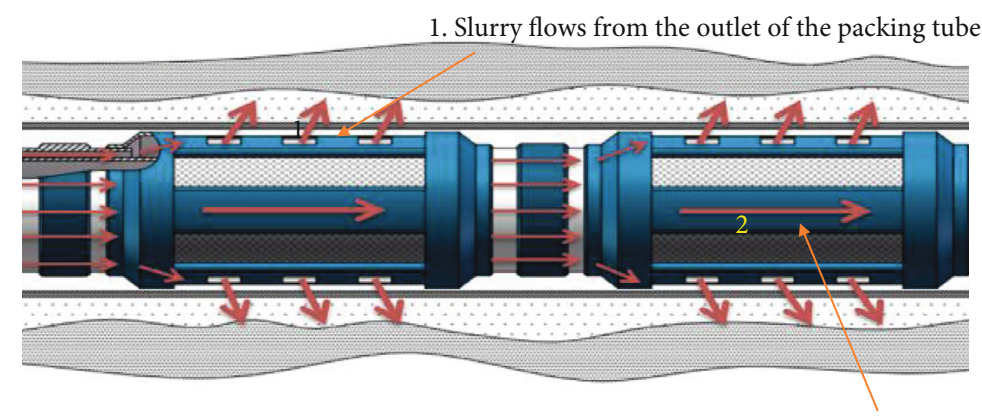

2. Slurry flows through transport tube

Figure 3: Principle of alternate path screen flow passage.

is the gravel concentration from the wellbore/screen annulus into the transport tube, dimensionless.

\subsection{Momentum Conservation Equation.}

$$
\left\{\begin{array}{l}
\rho_{p} \frac{Q_{p}}{A_{p}} \frac{\partial}{\partial x}\left(\frac{Q_{p}}{A_{p}}\right)=-\frac{\partial P_{p}}{\partial x}-F_{p}\left(Q_{p}\right) \\
\rho_{w} \frac{Q_{w}}{A_{w}} \frac{\partial}{\partial x}\left(\frac{Q_{w}}{A_{w}}\right)=-\frac{\partial P_{w}}{\partial x}-F_{w}\left(Q_{w}\right) \\
\rho_{s} \frac{Q_{s}}{A_{s}} \frac{\partial}{\partial x}\left(\frac{Q_{s}}{A_{s}}\right)=-\frac{\partial P_{s}}{\partial x}-F_{s}\left(Q_{s}\right) .
\end{array}\right.
$$

Once the specific relationship between $Q_{p w}, Q_{p r}$, and $Q_{p s}$ and pressure difference in (2) and the relationship between $F_{p}\left(Q_{p}\right), F_{w}\left(Q_{w}\right)$, and $F_{s}\left(Q_{s}\right)$ and respective flow rate in (4) are determined, the equations composed of (1) and (4) can solve $P_{p}, P_{w}, P_{s}, Q_{p}, Q_{w}$, and $Q_{s}$ and then substitute them into (3) to calculate the gravel concentration in the wellbore/screen annulus and transport tube.

During the gravel packing process of the shunted pipe, the slurry is transported from top to bottom along the wellbore, and the flow rate is related to the friction resistance. Therefore, the smaller the cross-sectional area, the less the flow rate. Whether the packing tube transmits the slurry is automatically adjusted according to the flow resistance. When the flow resistance in the wellbore/screen annulus is small, the packing tube does not transmit or transmits at the same time. Then, the shunted pipe must transmit once the sand bridge form in the wellbore/screen annulus. The packing of the section in front of the sand bridge is a complicated process. That is, part of the slurry is packed with $\beta$ wave and part of the slurry is packed to the lower part along the shunted pipe, which is continuous and simultaneous. The flow and packing process are based on the relationship between friction resistance and flow rate. The flow relationship is automatically adjusted, where the friction is large, the flow is less, and the slurry flow rate is less.

\section{Friction Resistance Analysis for Gravel Packing System}

Shunted screen gravel packing is a very effective gravel packing completion technology for the special situation of low formation fracture pressure and long wellbore length. The low fracture formation pressure requires that the packing pressure should not be too high in the gravel packing process, so as to avoid fracturing the formation and causing serious loss of carrier fluid. To complete the gravel packing of long wellbore, the carrier fluid should have sufficient sand carrying capacity to carry gravel to the end of the wellbore. Otherwise, the gravel may deposit too much when the slurry flows in the wellbore/screen annulus. If the height of the sand bed is too high, a sand bridge will form in the wellbore/screen annulus and the packing will stop. Sufficient sand-carrying capacity requires a sufficient pump rate, which will result in higher packing pressure. Therefore, for the horizontal open hole gravel packing, it is necessary to have the corresponding pump rate safety interval. For 


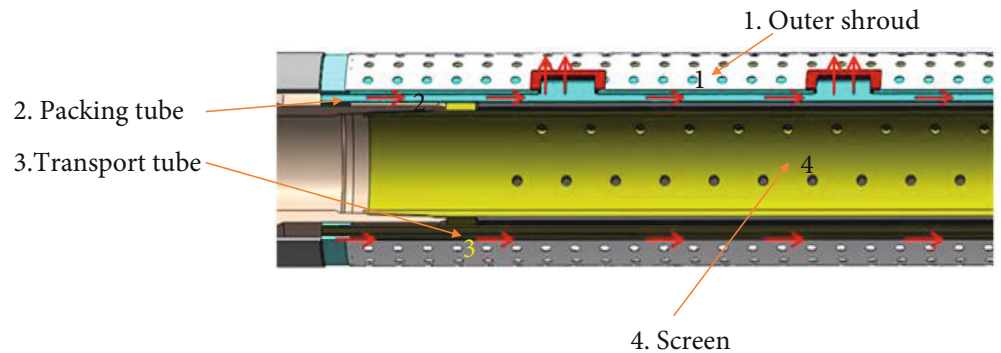

Figure 4: Schematic diagram of alternate path screen gravel packing.

TABLE 1: Basic parameters of A10H well in LS 17-2 gas field.

\begin{tabular}{lccc}
\hline Parameter & Numerical value & Parameter & Numerical value \\
\hline Open hole section $(\mathrm{m})$ & $3854.6-4198$ & Formation leakage rate $(\%)$ & Open hole diameter (in) \\
Wellbore length $(\mathrm{m})$ & 343.4 & Pump rate $(\mathrm{bpm})$ & 8.80 \\
Vertical depth of horizontal section $(\mathrm{m})$ & 3424 & Sand ratio $(\mathrm{ppg})$ & 5.6 \\
Reservoir pressure $(\mathrm{MPa})$ & 40.4 & Density of carrier fluid $\left(\mathrm{kg} / \mathrm{m}^{3}\right)$ & 1350 \\
Drill pipe & $5-7 / 8^{\prime \prime}$ drill pipe $+5^{\prime \prime}$ drill pipe & Apparent density of gravel $\left(\mathrm{kg} / \mathrm{m}^{3}\right)$ & 2400 \\
Equivalent outer diameter of screen tube (in) & 6.25 & & \\
Washpipe (in) & $3-1 / 2$ & & \\
\hline
\end{tabular}

extreme conditions, such as deepwater and low fracture pressure formations, such safety zones may not exist with conventional techniques. According to its unique design, the shunted screen gravel packing is equipped with transport tubes and packing tubes in the wellbore annulus. According to the selfadaptability of flow resistance, the slurry flow of different channel is automatically adjusted. If it is blocked, it will shunt the blockage through the transport tube and continue to the annulus behind the sand bridge through the packing tube. Therefore, the calculation and analysis of friction resistance are particularly important in different packing stages.

When designing gravel packing tools in the LS 17-2 gas field in the South China Sea, a pressure gauge was installed on the washpipe in order to timely and accurately analyze the changes in bottom hole pressure. Based on the packing mechanism and the friction calculation model at each stage and the actual basic data on site, the frictional resistance at each stage was calculated and the calculation results were compared with the on-site construction data in this paper. The shunted screen gravel packing diagram is shown in Figure 4.

The open hole gravel packing in horizontal wells can be divided into three stages: slurry injection stage, $\alpha$-wave packing stage, and $\beta$-wave packing stage [23].

4.1. Friction Loss in String. In the slurry injection stage, slurry flows along the string after injection at the wellhead, and the flow resistance in the string can be calculated according to the flow position of the slurry front. Friction loss in the string is

$$
\Delta P_{i}=\frac{32 f \rho_{m} Q_{p}^{2} L_{i}(t)}{\pi^{2} D_{c}^{5}}+\frac{32 f \rho_{f}\left(L_{c}-L_{i}(t)\right)}{\pi^{2} D_{c}^{5}}
$$

4.2. Friction Loss of Open Hole Wellbore during $\alpha$-Wave Packing Stage. Once the slurry enters the wellbore/screen annulus, the frontier position of slurry is the demarcation point. Along the flow direction, slurry flows behind the frontier position, and liquid flows in the front of the frontier position. This stage is the $\alpha$-wave packing stage, and the flow resistance at this stage is

$$
\Delta P_{\alpha}=\frac{2 f \rho_{m} Q_{p}^{2} L_{\alpha}(t)}{A_{u p}^{2} D_{u p}}+\frac{2 f \rho_{f} Q_{p}^{2}\left(L-L_{\alpha}(t)\right)}{A_{\mathrm{an}}^{2} D_{\mathrm{an}}}
$$

4.3. Friction Loss of Open Hole Wellbore during $\beta$-Wave Packing Stage. After $\alpha$-wave packing reaches the toe of the wellbore, the $\beta$-wave reverse packing stage begins. The flow resistance of this stage is as follows:

$\Delta P_{\beta}=\frac{2 f \rho_{m} Q_{p}^{2}\left(L-L_{\beta}(t)\right)}{A_{u p}^{2} D_{u p}}+\frac{32 f \rho_{f} Q_{p}^{2} L_{\beta}(t)}{\pi^{2}(2 / 3)^{1 / 2}\left(D_{i}^{2}-D_{e}^{2}\right)^{2}\left(D_{i}-D_{e}\right)}$,

where $\Delta P_{i}, \Delta P_{\alpha}$, and $\Delta P_{\beta}$ are friction loss, $\mathrm{Pa} ; Q_{p}$ is the pump rate, $\mathrm{m}^{3} / \mathrm{s} ; L_{c}$ is the depth of casing shoe, $\mathrm{m} ; L_{i}(t)$ is the depth of slurry injection at $t, \mathrm{~m} ; \rho_{m}$ and $\rho_{f}$ are the density of slurry and carrier liquid, respectively, $\mathrm{kg} / \mathrm{m}^{3} ; D_{c}$ is the diameter of string, $\mathrm{m} ; L, L_{\alpha}(t)$, and $L_{\beta}(t)$ are wellbore length and $\alpha$-wave packing front distance at time $t, \beta$-wave front distance at time $t, \mathrm{~m} ; A_{u p}$ and $A_{\mathrm{an}}$ are the cross-sectional area of the upper part of the sand bed and the crosssectional area of the wellbore/screen annulus, $\mathrm{m}^{2} ; f$ is the friction coefficient; $D_{u p}$ and $D_{\text {an }}$ are the hydraulic diameter of the upper channel of the sand bed and the hydraulic diameter of wellbore/screen annulus, $\mathrm{m} ; D_{i}$ and $D_{e}$ are the 
TABLE 2: Comparison of simulation results and operation results.

\begin{tabular}{|c|c|c|c|}
\hline Parameter & Model calculation results & Construction results & Errors and remarks \\
\hline$\alpha$-Wave packing length (m) & 343.4 & 343.4 & No error, packing can be completed \\
\hline$\beta$-Wave packing length (m) & 343.4 & 343.4 & No error, packing can be completed \\
\hline Total packing time (min) & 195.03 & 251 & $\begin{array}{l}100 \% \text { packing is considered in the simulation, } \\
\text { while } 138 \% \text { packing is achieved in the } \\
\text { actual operation, so the simulation time } \\
\text { is less than the actual packing time }\end{array}$ \\
\hline Total sand consumption (lbs) & 16371.8365 & $\begin{array}{l}16509 \text { (100\% packing), } \\
22800 \text { (138\% packing) }\end{array}$ & Error $<1 \%$ \\
\hline$\alpha$-Wave sand dune ratio & 0.7921 & 0.79 & Error $<1 \%$ \\
\hline
\end{tabular}

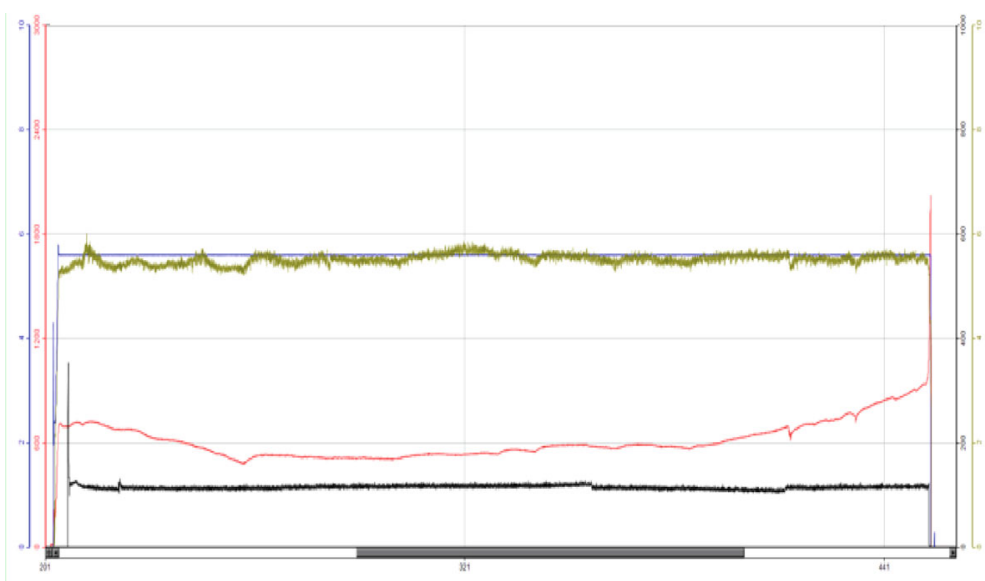

- Pack pressure (psi)

Time (min)

- Pump rate (bbl/min)

- Sand rate (lb/min)

- Annulus return rate (bbl/min)

(a) Sand control construction curve

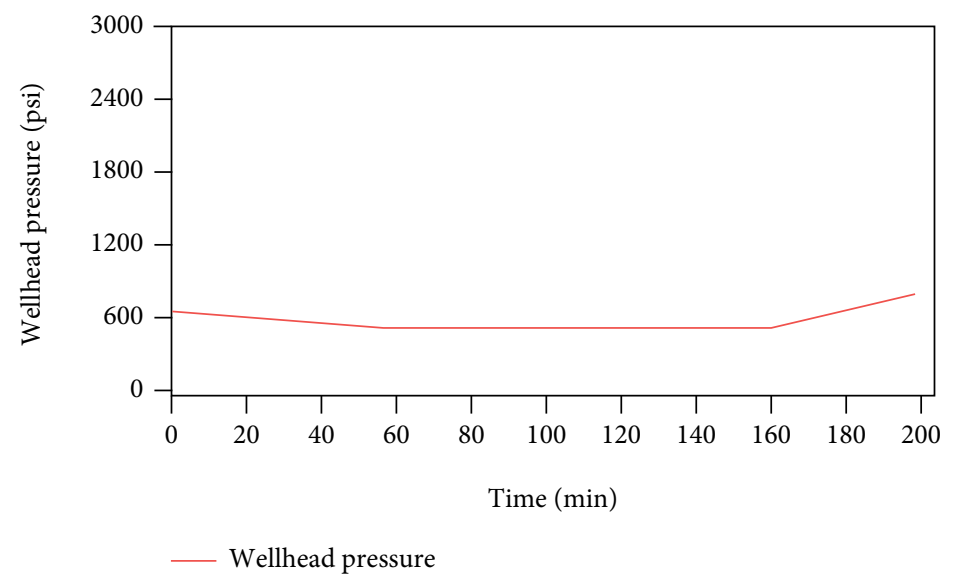

(b) Simulation calculation of wellhead pressure curve

Figure 5: Comparison of simulation results and construction results.

inner diameter of screen pipe and the outer diameter of washpipe, respectively, $\mathrm{m}$.

Given the actual data and combined with formulas (5), (6), and (7), the friction calculation at different stages can be carried out. The prediction and optimization can be made by comparing the calculated results with the operation results of the actual downhole pressure gauge in the field. 
TABLE 3: Construction and simulation results in different packing stages.

\begin{tabular}{|c|c|c|c|}
\hline & Model calculation results & $\begin{array}{c}\text { Sand control } \\
\text { construction results }\end{array}$ & Error and remarks \\
\hline $\begin{array}{l}\text { When starting to add sand, the wellhead } \\
\text { pump pressure (psi) }\end{array}$ & 670.95 & 697 & Error $<5 \%$ \\
\hline$\alpha$-Wave packing start pressure (psi) & 528.3456 & 501 & Error $<5 \%$ \\
\hline$\alpha$-Wave packing average pressure (psi) & 542.346 & 525 & Error $<5 \%$ \\
\hline$\beta$-Wave packing average pressure (psi) & 567.1467 & 580 & Error $<5 \%$ \\
\hline Pressure before screenout (psi) & 812.75 & 940 & $\begin{array}{l}\text { The simulation calculation considers } 100 \% \\
\text { packing, but the actual construction } \\
\text { reaches } 138 \% \text {, which leads to some errors }\end{array}$ \\
\hline
\end{tabular}

TABle 4: Downhole pressure gauge data logging.

\begin{tabular}{lccccc}
\hline $\begin{array}{l}\text { Serial } \\
\text { number }\end{array}$ & Packing state & $\begin{array}{c}\text { Lower outside-inside } \\
\text { difference }(\mathrm{psi})\end{array}$ & $\begin{array}{c}\text { Upper outer-inner } \\
\text { difference }(\mathrm{psi})\end{array}$ & $\begin{array}{c}\text { Top-bottom external } \\
\text { difference (psi) }\end{array}$ & $\begin{array}{c}\text { Bottom-up internal } \\
\text { difference }(\mathrm{psi})\end{array}$ \\
\hline 1 & Prepump stage & 3 & 1 & -41 & 39 \\
2 & Began to sand & 34 & 176 & 25 & 13 \\
3 & $\alpha$-Wave packing & 50 & 190 & 13 & 127 \\
4 & $\alpha$-Wave packing & 48 & 184 & 20 & 126 \\
5 & Stage 3-4 & 43 & 179 & 19 & 116 \\
6 & $\beta$-Wave initiation & 45 & 390 & 216 & 123 \\
7 & Screenout & 51 & 390 & \\
\hline
\end{tabular}

TABLE 5: Simulation results of friction distribution at each packing stage.

\begin{tabular}{lccc}
\hline & Injection stage & $\alpha$-Wave stage & $\beta$-Wave stage \\
\hline String injection friction (max), psi & 181.8335892 & 181.8338831 & 181.8338831 \\
Total friction in horizontal section (max), psi & 1.380201471 & 29.54096242 & 285.8021072 \\
Backflow friction of washpipe (max), psi & 119.5657029 & 119.5657029 & 119.5657029 \\
Annular friction between string and casing (max), psi & 81.82761718 & 81.82761718 & 81.82761718 \\
\hline
\end{tabular}

\section{Filed Case Histories and Application}

5.1. Comparative Analysis of Packing Simulation Results and Construction Results. LS 17-2 gas field is a deepwater gas field in the South China Sea. Water depth is approximately $1252 \sim 1530 \mathrm{~m}$, and the reservoir buried depth is approximately $3200 \sim 3400 \mathrm{~m}$. The reservoir pressure coefficient is approximately 1.19 1.21, and reservoir pressure is approximately 39.0 40.3 MPa. The reservoir temperature is approximately $85 \sim 95.1^{\circ} \mathrm{C}$, and the permeability is approximately $89.0 \sim 2512.3 \mathrm{mD}$; the average permeability is $543.0 \mathrm{mD}$. The physical properties are high porosity extra high porosity, high permeability extra high permeability. The median particle size is between 67.0 and $250.0 \mu \mathrm{m}$. The clay content is approximately $21.0 \% \sim 27.0 \%$. Using the prediction methods of acoustic time difference, $\mathrm{B}$ index, and $\mathrm{S}$ index, there is a great risk of sand production. So gravel packing is recommended for sand control. There are 11 development wells (6 horizontal wells and 5 vertical wells) in LS 17-2 gas field, with a total footage of $41171 \mathrm{~m}$. An average well depth is
$3743 \mathrm{~m}$, and a maximum well depth is $4054 \mathrm{~m}$. A maximum horizontal displacement is $927 \mathrm{~m}$, and a maximum well inclination is $90^{\circ}$. A shunted screen is used for gravel packing in well $\mathrm{A} 10 \mathrm{H}$, and a pressure gauge is installed above and below the washpipe of the downhole packing tool to monitor the pressure change in the packing process in real time.

Corresponding gravel packing process and mechanism, the calculation software was developed to calculate and simulate the friction at different stages of the packing process. The parameters of the $\alpha$ - $\beta$ wave packing stage and the screenout pressure and then compared with the construction results were calculated and analyzed. The basic parameters of well $\mathrm{A} 10 \mathrm{H}$ are shown in Table 1.

The simulation calculation results are shown in Table 2. From the data in the table, it can be seen that the simulation calculation results of $\alpha$ - $\beta$ packing length and $\beta$-wave packing length are completely consistent with the operation results. If the total packing time is considered $100 \%$ packing in theory, the error between the calculation results and the 


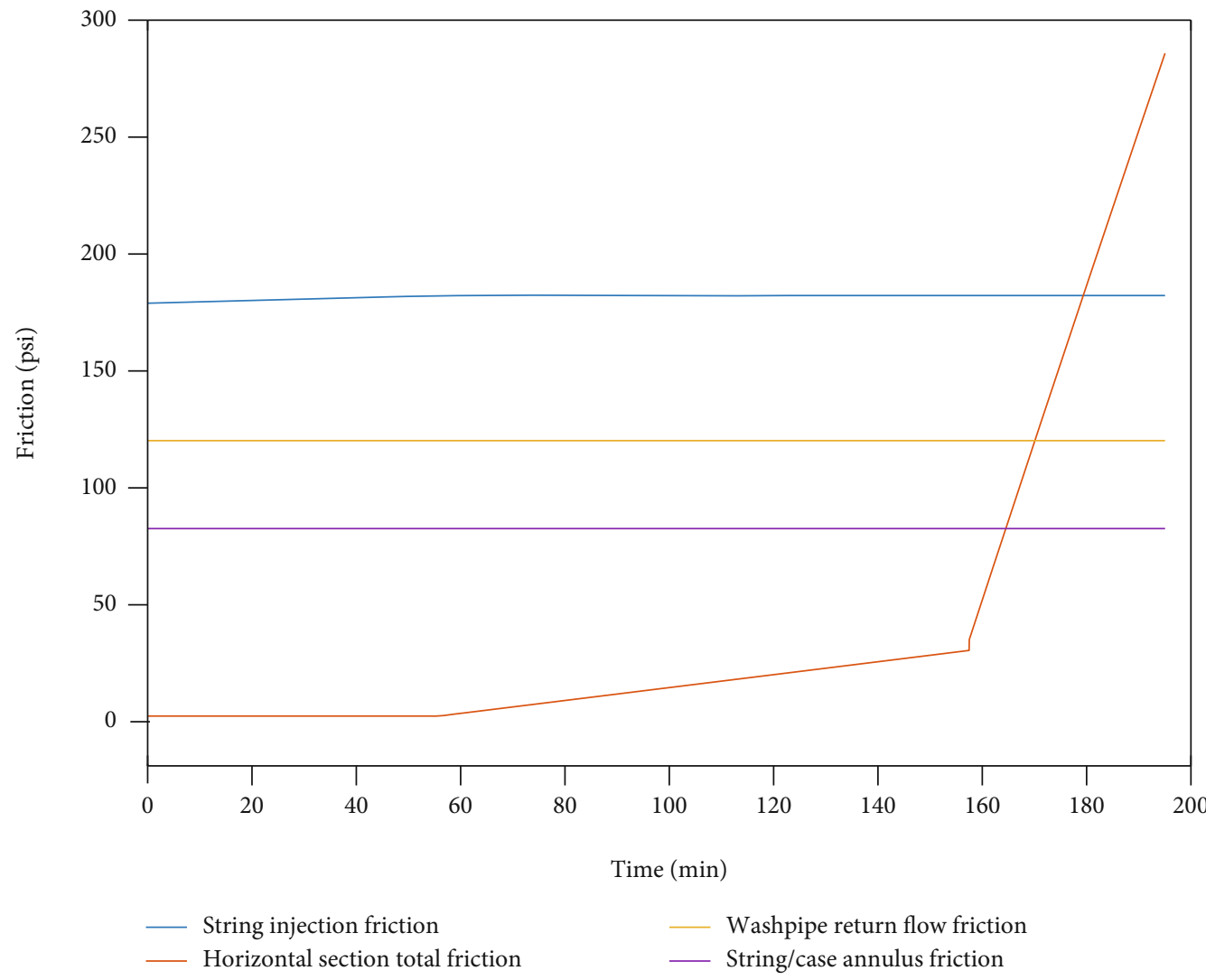

FIgURE 6: Friction distribution at different packing position vs. time.

operation results is less than $10 \%$. At the same time, the total sand consumption and sand dune ratio error are both less than $1 \%$.

5.2. Comparative Analysis of Packing Pressure. According to the friction calculation models at different stages, the corresponding software was compiled and calculated. The comparison of the packing pressure calculated by the simulation and the on-site operation results is shown in Figure 5. It can be seen from the figure that the pressure change trend tends to be consistent. At the same time, the pressure calculation and operation results before starting to add sand, $\alpha$-wave packing, $\beta$-wave packing, and screenout are shown in Table 3. The error is less than 5\%; the simulation accuracy is high and can meet the requirements.

Table 4 shows the data recording results of the downhole pressure gauge. According to the design position of the pressure gauge, numerical simulation calculations were carried out using the compiled software. The calculation results are shown in Table 5.

As can be seen from Tables 4 and 5, the calculation simulation results and the downhole pressure gauge test results are as follows: the maximum value of the external difference between upper and lower is $20 \mathrm{psi}$ at the $\alpha$-wave stage, which is roughly the horizontal packing friction and the calculated value is $29.54 \mathrm{psi}$. This calculation result should be reasonable considering the deviation of position. The maximum difference between upper and lower was $216 \mathrm{psi}$ in the $\beta$ wave stage, and the calculated value of packing friction resis-

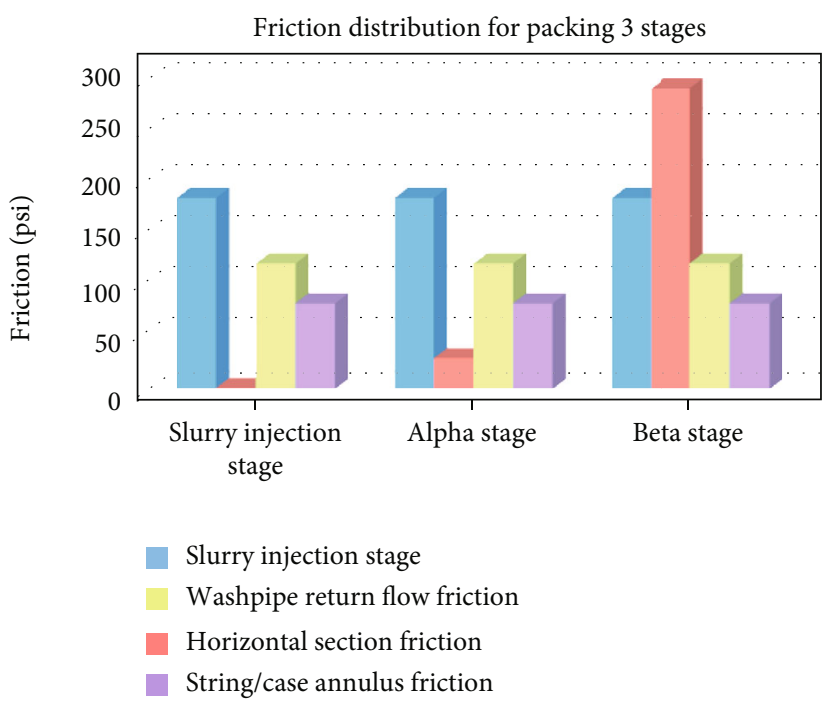

FIGURE 7: Friction distribution in three packing stages.

tance in the horizontal section was 285.802 psi. The internal difference between the bottom and top is about 120 psi, which roughly reflects the friction resistance of the washpipe, and the calculated value is $119.5657 \mathrm{psi}$, which are within manageable margins of error.

Figure 6 shows the calculated and simulated frictional distribution at different positions of gravel packing with packing time. It can be seen that the total frictional 
distribution in the horizontal section increases rapidly in the $\beta$-wave stage, resulting in high packing pressure and easy fracturing formation.

Figure 7 is to calculate the slurry injection stage, $\alpha$-wave and $\beta$-wave packing stage corresponding friction calculation contrast. It can be seen that in deepwater wells, in the slurry injection stage and $\alpha$-wave packing stage, the string friction proportion is the largest. During the $\beta$-wave packing stage, with the need of carrier fluid through a long narrow washpipe/screen annulus, friction increases quickly. Therefore, this packing stage is the stage of maximum of packing pressure.

\section{Conclusions}

(1) Shunted screen gravel pack uses its unique design structure, when there is a sand bridge in the wellbore annulus, according to the flow resistance and flow adaptability, the slurry can be introduced across the sand bridge to pack the back of the annulus. This technology is suitable for gravel packing in low fracture pressure formations and long horizontal wells

(2) According to the mechanism analysis of shunted screen gravel packing technology and the friction calculation model established, the developed gravel packing simulation software can accurately predict the change of friction in the packing process. According to the friction at different positions, the flow direction of slurry in the transport pipe and wellbore annulus can be judged and then the change of flow parameters in the transport pipe can be calculated. The calculated results are in good agreement with the construction results

(3) Through mutual checking of the data obtained from the downhole pressure gauge and the results of simulation calculation, the packing effect can be further predicted and the parameters can be optimized to ensure the success of gravel packing in the field

\section{Data Availability}

All data, models, and code generated or used during the study appear in the submitted article.

\section{Conflicts of Interest}

The authors declare that they have no conflicts of interest.

\section{Acknowledgments}

This work was financially supported by the Scientific Research Project of CNOOC (China) Co. Ltd: Key technology research on drilling and completion of 20 million cubic meters of oil field in the west of South China Sea (CNOOCKJ135ZDXM38ZJ05ZJ). We sincerely thank other persons in the China University of Petroleum for helping with the model established.

\section{References}

[1] Z. Chen, R. J. Novotny, R. Farias, A. Mendez, C. A. Pedroso, and L. H. C. Fernandes, "Gravel packing deep water long horizontal wells under low fracture gradient," in Paper presented at the SPE Annual Technical Conference and Exhibition, pp. 1-18, Houston, Texas, 2004.

[2] Z. Shengtian, L. Zhaomin, and D. Changyin, "The advances of numerical simulation for gravel packing in horizontal wells," Mechanics and Practice., vol. 31, no. 3, pp. 9-15, 2009.

[3] Z. Chen, "The application of light and ultra-light weight proppant in horizontal well sand control: unified model and case histories," in Paper presented at the SPE Deepwater Drilling and Completions Conference, pp. 1-12, Galveston, Texas, USA, 2012.

[4] A. T. Jardim Neto, F. G. M. Prata, J. R. R. Gomez, C. A. A. Pedroso, M. O. O. Martins, and D. N. N. Silva, "Ultralightweight proppants: an effective approach to address problems in long horizontal gravel packs offshore Brazil," SPE Drilling \& Completion, vol. 27, no. 4, pp. 613-624, 2012.

[5] R. Farias, J. Li, A. Vilela, and R. S. Aboud, "Openhole horizontal gravel packing offshore Brazil: best practices and lessons learned from 72 operations," in Paper presented at the Latin American \& Caribbean Petroleum Engineering Conference, pp. 1-19, Buenos Aires, Argentina, 2007.

[6] B. Baser, S. Shenoy, B. Gadiyar, S. Jain, and M. Parlar, "An alternative method of dealing with pressure: friction reducer for water packing of long horizontal open holes in lowfracturing-gradient environments," SPE Drilling \& Completion, vol. 25, no. 3, pp. 300-308, 2010.

[7] W. Meng, S. Zhou, D. Jiang et al., "Research on low-density gravel packing technique plan for long horizontal wells in offshore sup-shallow gas pools," China Offshore Oil and Gas., vol. 31, no. 3, pp. 147-151, 2019.

[8] L. G. Jones, C. S. Yeh, T. J. Yates, D. W. Bryant, M. W. Doolittle, and J. C. Healy, "Alternate path gravel packing," in Paper presented at the SPE Annual Technical Conference and Exhibition, pp. 391-398, Dallas, Texas, 1991.

[9] C. S. Yeh, S. Clingman, B. A. Dale et al., "Unlocking the limits of extreme length in alternate path gravel packing," in IPTC 12549, International Petroleum Technology Conference, pp. 113, Kuala Lumpur, Malaysia, 2008.

[10] B. N. Rao and A. M. Amin, "A flow simulator for the design of extreme-length gravel packs utilizing alternate-path technology," in Paper presented at the SPE International Symposium and Exhibition on Formation Damage Control, p. SPE128068-MS, Lafayette, Louisiana, USA, 2010.

[11] A. Kumar, B. Gadiyar, M. Langlais, G. Woiceshyn, A. Dikshit, and M. Parlar, "Development and qualification of enhanced shunted screens for openhole gravel packing of long intervals," in Paper presented at the SPE Annual Technical Conference and Exhibition, Virtual, p. SPE-201731-MS, Denver, Colorado, USA, 2020.

[12] J. Jeanpert, T. Banning, C. Abad, I. Mbamalu, and J. Hardy, "Successful installation of horizontal openhole gravel-pack completions in low fracture gradient enviroment: a case history from deepwater west Africa," in Paper presented at the SPE International Conference and Exhibition on Formation Damage Control, p. SPE-189492-MS, Lafayette, Louisiana, USA, 2018.

[13] M. T. Hecker, M. D. Barry, C. M. Sweeney, S. P. Arnold, and C. S. Yeh, "Extending openhole gravel packing capability: 
initial field installation of internal shunt alternate path technology," in Paper presented at the SPE Annual Technical Conference and Exhibition, p. SPE-135102-MS, Florence, Italy, 2010.

[14] B. N. Rao, A. M. Amin, R. Van Petegeg, and J. Broussard, "On the hydraulics of inverted flow path gravel pack operations," in Paper presented at the SPE International Symposium and Exhibition on Formation Damage Control, p. SPE-151803-MS, Lafayette, Louisiana, USA, 2012.

[15] A. Mimouna, A. Verma, and M. N. Guddati, "Generalized framework to simulate gravel packing in wellbore completions," in Paper presented at the Offshore Technology Conference, p. OTC-28683-MS, Houston, Texas, USA, 2018.

[16] L. G. Jones, R. J. Tibbles, L. Myers, D. Bryant, J. Hardin, and G. Hurst, "Gravel packing horizontal wellbore with leak-off using shunts," in Paper presented at the SPE Annual Technical Conference and Exhibition, p. SPE-38640-MS, San Antonio, Texas, 1997.

[17] P. M. Saldungaray, J. C. Troncoso, and B. T. Santoso, "Simultaneouus gravel packing and filter cake removal in horizontal wells applying shunt tubes and novel carrier and breaker fluid," in Paper presented at the SPE Middle East Oil Show, p. SPE-68205-MS, Manama, Bahrain, 2001.

[18] K. Godwin, B. Gadiyar, and H. Riordan, "Simultaneous gravel packing and filtercake cleanup with shunt tubes in open-hole completions: a case history from the Gulf of Mexico," in Paper presented at the SPE Annual Technical Conference and Exhibition, p. SPE-71672-MS, New Orleans, Louisiana, 2001.

[19] G. Hurst, S. D. Cooper, W. D. Norman et al., "Alternate path completions: a critical review and lessons learned from case histories with recommended practices for deepwater applications," in Paper presented at the SPE International Symposium and Exhibition on Formation Damage Control, p. SPE-86532MS, Lafayette, Louisiana, 2004.

[20] A. Dikshit, A. Kumar, M. Langlais, B. Gadiyar, G. Woiceshyn, and M. Parlar, "Extending openhole gravel-packing intervals through enhanced shunted screens," SPE Drilling and Completion, vol. 36, no. 2, pp. 445-458, 2021.

[21] P. Pillai, C.-C. Lin, J. Brege et al., "Industry first openhole alternate path gravel pack completion in HPHT environment: fluid development and caase history," in Paper presented at the SPE Annual Technical Conference and Exhibition, p. SPE-206048MS, Dubai, UAE, 2021.

[22] S. Saebi, "The evolution of completion designs using alternate path (shunt-tubes) technology," in Paper presented at the SPE Oil and Gas India Conference and Exhibition, p. SPE-155129MS, Mumbai, India, 2012.

[23] A. L. Martins, J. V. M. de Magalhaes, A. Calderon, and C. M. Chagas, "A mechanistic model for horizontal gravel pack displacement,” SPE Journal, vol. 10, no. 3, pp. 229-237, 2005. 